\title{
The climate in the Baltic Sea region during the last millennium simulated with a regional climate model
}

\author{
S. Schimanke, H. E. M. Meier, E. Kjellström, G. Strandberg, and R. Hordoir \\ Swedish Meteorological and Hydrological Institute, 60176 Norrköping, Sweden \\ Correspondence to: S. Schimanke (semjon.schimanke@ smhi.se) \\ Received: 30 March 2012 - Published in Clim. Past Discuss.: 20 April 2012 \\ Revised: 12 July 2012 - Accepted: 19 August 2012 - Published: 7 September 2012
}

\begin{abstract}
Variability and long-term climate change in the Baltic Sea region is investigated for the pre-industrial period of the last millennium. For the first time dynamical downscaling covering the complete millennium is conducted with a regional climate model in this area. As a result of changing external forcing conditions, the model simulation shows warm conditions in the first centuries followed by a gradual cooling until ca. 1700 before temperature increases in the last centuries. This long-term evolution, with a Medieval Climate Anomaly (MCA) and a Little Ice Age (LIA), is in broad agreement with proxy-based reconstructions. However, the timing of warm and cold events is not captured at all times. We show that the regional response to the global climate anomalies is to a strong degree modified by the large-scale circulation in the model. In particular, we find that a positive phase of the North Atlantic Oscillation (NAO) simulated during MCA contributes to enhancing winter temperatures and precipitation in the region while a negative NAO index in the LIA reduces them. In a second step, the regional ocean model (RCO-SCOBI) is used to investigate the impact of atmospheric changes onto the Baltic Sea for two $100 \mathrm{yr}$ time slices representing the MCA and the LIA. Besides the warming of the Baltic Sea, the water becomes fresher at all levels during the MCA. This is induced by increased runoff and stronger westerly winds. Moreover, the oxygen concentrations in the deep layers are slightly reduced during the MCA. Additional sensitivity studies are conducted to investigate the impact of even higher temperatures and increased nutrient loads. The presented experiments suggest that changing nutrient loads may be more important determining oxygen depletion than changes in temperature or dynamic feedbacks.
\end{abstract}

\section{Introduction}

The climate of the last millennium is characterised by large long-term variability. Warmer conditions prevailed in large parts of the Northern Hemisphere at the beginning of the last millennium (950-1250 AD) with colder conditions thereafter (1400-1700 AD) (e.g. Mann et al., 2009; Ljungqvist et al., 2012). These periods are known as the Medieval Climate Anomaly (MCA) and the Little Ice Age (LIA), whereas the exact period varies between different studies. The man-made contributions to climate change were small in these ancient times. Therefore, differences between periods prior to 1850 reflect internal unforced variability and changes in natural external forcing. Many studies reveal that such long-term variability can be triggered by the sun (e.g. Haigh, 1996; Guiot et al., 2010) since the sun's irradiation varies over time scales from days to millennia (Lean, 2005). Another source of influence comes from strong volcanic eruptions. These can considerably reduce hemispheric mean temperature over several years (Timmreck et al., 2009). Here, the discussion is ongoing if solar or volcanic forcing was more important for the climate evolution in the last millennium (Jungclaus et al., 2010). Moreover, model studies indicate that natural unforced long-term variability could have significantly contributed to form the exceptional periods of the MCA and the LIA (Mann et al., 2009; Jungclaus et al., 2010).

Apart from the direct effects of external forcing, regional temperature variability in Europe is affected by changes in the North Atlantic Oscillation (NAO) (Hurrell, 1995). Proxy data (Mann et al., 2009; Trouet et al., 2009) and model studies (Gómez-Navarro et al., 2011) indicate that a positive NAO index prevailed during the MCA, whereas the NAO index was negative during the LIA (Spangehl et al., 2010). 
However, the influence of the NAO on the temperature in the Baltic Sea region is limited (Kauker and Meier, 2003). Nevertheless, for anomalies of the NAO it is known that the location and intensity of storm tracks is affected (e.g. Spangehl et al., 2010) leading to anomalies in precipitation. Here, results based on tree rings show diverging results in Northern Europe for the key periods of the MCA and the LIA. For instance, Jönsson and Nilsson (2009) reveal evidence that large parts of the LIA (namely 1560-1590 and 1657-1675 AD) were drier, whereas Helama et al. (2009) points out that it was wetter from 1220 until $1650 \mathrm{AD}$.

Model studies focusing on the climate evolution of the last millennium have so far generally been conducted with global climate models (GCMs) even if they sometimes focus on certain regions (Gouirand et al., 2007). This limits the comparison of model results with proxies as tree rings, which are effected by regional/local features that might not be represented appropriately in GCMs. Dynamical downscaling is one possibility to increase the resolution and include local effects into the model results. However, the finer resolution of regional climate models (RCMs) demands more computer power and restricts its application. As a consequence, no downscaling approach exists for the entire Baltic Sea region covering the entire millennium so far. A long integration of in total $600 \mathrm{yr}$ has been done with an earlier version of RCA3, although only at relatively coarse resolution and not covering the full Baltic Sea catchment area (Graham et al., 2009). For the Iberian Peninsula, a first dynamical downscaling experiment was conducted for the whole millennium by GómezNavarro et al. (2011). They found good agreement between their modelled temperature (used model is RCM MM5) and proxy-based reconstructions. We present in this study first results of a regional climate model simulation for the last millennium including most of Europe, where we focus on the Baltic Sea region.

Moreover, the downscaled atmospheric conditions are used to simulate the response of the Baltic Sea to changing forcing conditions with the Rossby Centre ocean model with interactive biogeochemistry (RCO-SCOBI). The Baltic Sea is one of the largest inland brackish seas with an estuarinelike circulation and sensitive to changes in the environmental conditions. For instance, it is known from sediment studies that the deep bottom layers were hypoxic during the MCA in contrast to the LIA (Zillén and Conley, 2010; Kabel et al., 2012). The period of hypoxia during the MCA correlate to population growth and large-scale changes in land use and with it the input of nutrients (Zillén and Conley, 2010). Following their argumentation, salinity and temperature anomalies cannot explain hypoxia during the MCA. Therefore, it resulted from anthropogenic impacts (Zillén et al., 2008; Zillén and Conley, 2010) similarly to the 20th century (Conley et al., 2009; Hansson and Gustafsson, 2011; Gustafsson et al., 2012). However, historical nutrient loads are not estimated yet and the effect of pure natural climate change during the MCA has not been investigated so far.
Baltic Sea ocean model studies of the period before 1900 are very rare until today. Hansson and Gustafsson (2011) used the PROBE-Baltic ocean model to simulate Baltic Sea conditions during the last $500 \mathrm{yr}$. Their results indicate a strong decrease of bottom oxygen only after 1950 with no significant signals before including the LIA. They suggest that increased nutrient inputs most likely dominate the expansion of hypoxic bottom areas during the last century. This is in agreement with other shorter reconstruction starting in 1850 (Gustafsson et al., 2012) and 1902 (Meier and Kauker, 2003), respectively. However, it is in contrast to the recently published study by Kabel et al. (2012). They suggest that changes in the sea surface temperatures (SSTs) are more relevant than the prevailing nutrient supply. So, it is still an open question whether temperature anomlies or eutrophication was responsible for anoxic conditions during the MCA and, in general, little is known about the pristine state of the Baltic Sea earlier during the last millennium.

In this study, we investigate climate variability in the Baltic Sea and its surrounding area for the pre-industrial period of the last millennium with the MCA and LIA as key periods. We present the first regional climate simulation for this area covering the full millennium. Variability of atmospheric parameters connected to the forcing and internal variability are discussed. Here, we focus on parameters relevant for the state of the Baltic Sea as temperature, precipitation, and wind speed. The large-scale atmospheric circulation is compared to that derived from proxy-based reconstructions of the NAO index. Results of the ocean model are used to highlight to what degree these changes effect the Baltic Sea. Especially, we focus on the question which factor, temperature or nutrient supply, was more important for the development of anoxia during the MCA.

The paper is organised as follows: in Sect. 2 the models and the experimental setup is described. Section 3 focus on changes of the atmosphere, whereas in Sect. 4 effects on the Baltic Sea are investigated. The results are summarised and discussed in Sect. 5.

\section{Models and experiments}

\subsection{Model description}

\subsubsection{The Rossby Centre regional climate model}

The Rossby Centre Regional Climate model version 3 (RCA3, Samuelsson et al., 2011) is based on the numerical weather prediction model HIRLAM (Unden et al., 2002). In the present setup it operates on a rotated longitude-latitude grid with a horizontal resolution of $0.44^{\circ}$ (approx. $50 \mathrm{~km}$ ). Here, RCA3 is run with 24 vertical levels and a time step of $30 \mathrm{~min}$. The model domain with its $102 \times 111$ grid boxes is shown in Fig. 1. RCA3 has a tiled surface scheme including a detailed snow storage parametrisation over land. Lake 


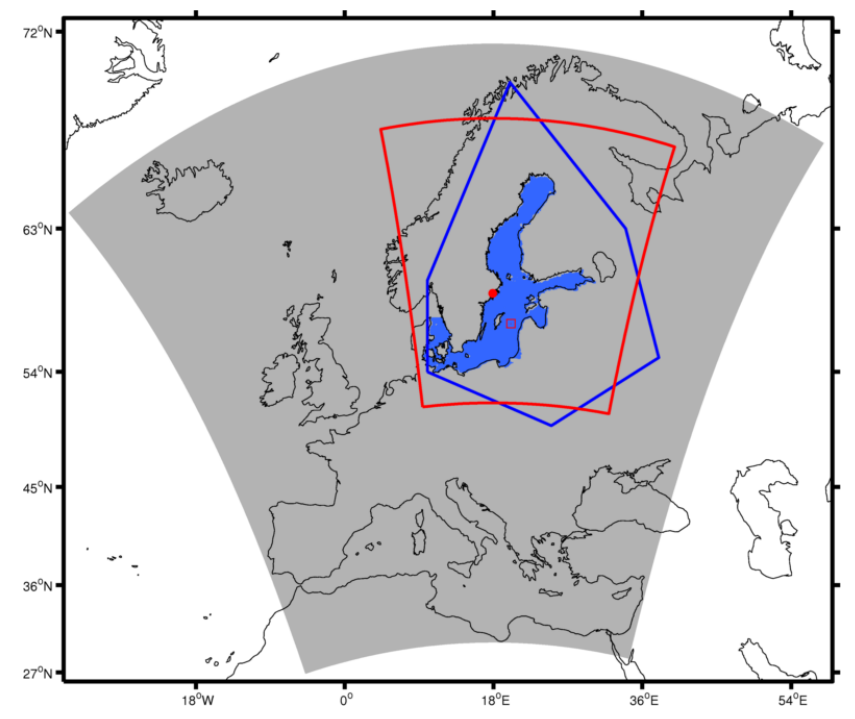

Fig. 1. The model domains of RCA (grey) and RCO (blue) are highlighted together with specific locations. The location of the temperature reconstruction side by Leijonhufvud et al. (2010) is marked with a red point, whereas the location of the Gotland Deep is indicated by a square. The framed areas indicate the averaging areas for the Baltic region temperature (red) and the catchment area (blue).

surfaces are simulated with a lake model, whereas the SSTs are taken from the driving GCM.

RCA3 has been used and verified for many applications ranging from paleo (Kjellström et al., 2010; Strandberg et al., 2011) to future simulations (Kjellström et al., 2011; Nikulin et al., 2011). The model is in good agreement with observations if it is forced with ECMWF re-analysis-40 (ERA40, Uppala et al., 2005) boundary conditions. The small biases include a too high MSLP in the Mediterranean region, a warm bias in the northeastern part, a cold bias in Southern Europe and North Africa, and an underestimation of the diurnal temperature cycle (Samuelsson et al., 2011). The finer resolution contributes to a better captured geographical distribution of precipitation in RCA3 than in ERA40 (Lind and Kjellström, 2009; Samuelsson et al., 2011). For a more detailed model description and validation we refer to Samuelsson et al. (2011).

In this study, the driving global climate model is ECHO$\mathrm{G}$ (Legutke and Voss, 1999). ECHO-G consists of the spectral atmospheric GCM ECHAM4 and the coupled oceanthermodynamic sea ice model HOPE-G. ECHO-G has been used and evaluated for many paleo climate studies (e.g. Zorita et al., 2005; Kaspar et al., 2007). The internal generated variability of the NAO is similar to the variability in observations, and the correlation of the NAO index with precipitation and the 2-m air temperature is adequate (Min et al., 2005).

\subsubsection{The Rossby Centre ocean model with interactive biogeochemistry}

We use the Rossby Centre ocean model (RCO) coupled with the Swedish Coastal and Ocean Biogeochemical model (SCOBI, Eilola et al., 2009) abbreviated as RCO-SCOBI. The domain covers the entire Baltic Sea (Fig. 1). RCO is a Bryan-Cox-Semtner primitive equation circulation model with a free surface (Killworth et al., 1991) and open boundary conditions (Stevens, 1991) in the Northern Kattegat. It has a horizontal resolution of two nautical miles (about $3.7 \mathrm{~km}$ ). The 83 vertical layers are equally thick with a layer thickness of $3 \mathrm{~m}$. The baroclinic and barotropic time steps amount to 150 and $15 \mathrm{~s}$, respectively. The sea surface height (SSHs) at the open boundary in the Northern Kattegat between Denmark and Sweden is based on SLP gradients over the North Sea taken from the RCA3 simulation. In the case of inflowing water temperature and salinity are nudged towards climatological profiles. For a detailed model description the reader is referred to Meier et al. (2003) and Meier (2007).

The coupled biogeochemical model SCOBI simulates the dynamics of nitrate, ammonium, phosphate, phytoplankton, zooplankton, detritus, and oxygen. RCO-SCOBI is able to simulate the climate of the recent past in agreement with observations and is in the range of other state-of-the-art biogeochemical models (Eilola et al., 2011). For more details, the reader is referred to Eilola et al. (2009, 2011); Meier et al. (2012b).

RCO-SCOBI is forced with $10 \mathrm{~m}$ wind, 2-m air temperature, 2-m specific humidity, precipitation, total cloudiness and sea level pressure fields from RCA3. The SSH and river runoff are calculated based on the RCA3 data following Meier et al. (2012a).

\subsection{Experimental setup}

RCA3 is forced with an ECHO-G simulation starting at 7000 BP (Wagner et al., 2007; Hünicke et al., 2010). The ECHO-G model is forced with variations in orbital parameters, solar irradiance and greenhouse gases between $7000 \mathrm{BP}$ and $1998 \mathrm{AD}$. Since the focus in this study is on the last millennium we use boundary conditions from 950 AD until 1998 AD to force RCA3. A more elaborative description of the ECHO-G Holocene simulation can be found in Hünicke et al. (2010).

Figure 2 shows the evolution of the $\mathrm{CO}_{2}$ concentration and the solar insolation as prescribed for ECHO-G and RCA3. The variability of the $\mathrm{CO}_{2}$ concentration is relatively small in the pre-industrial period. Until 1850 the $\mathrm{CO}_{2}$ concentration varies between 270 and 290 ppmv. A rapid increase occurs thereafter which is known to be of anthropogenic origin. Towards the end of the simulation the $\mathrm{CO}_{2}$ concentration reaches values of more than 360 ppmv.

Variations in solar radiation appear during the whole millennium. The most distinct minima were the Oort, the Spörer, 

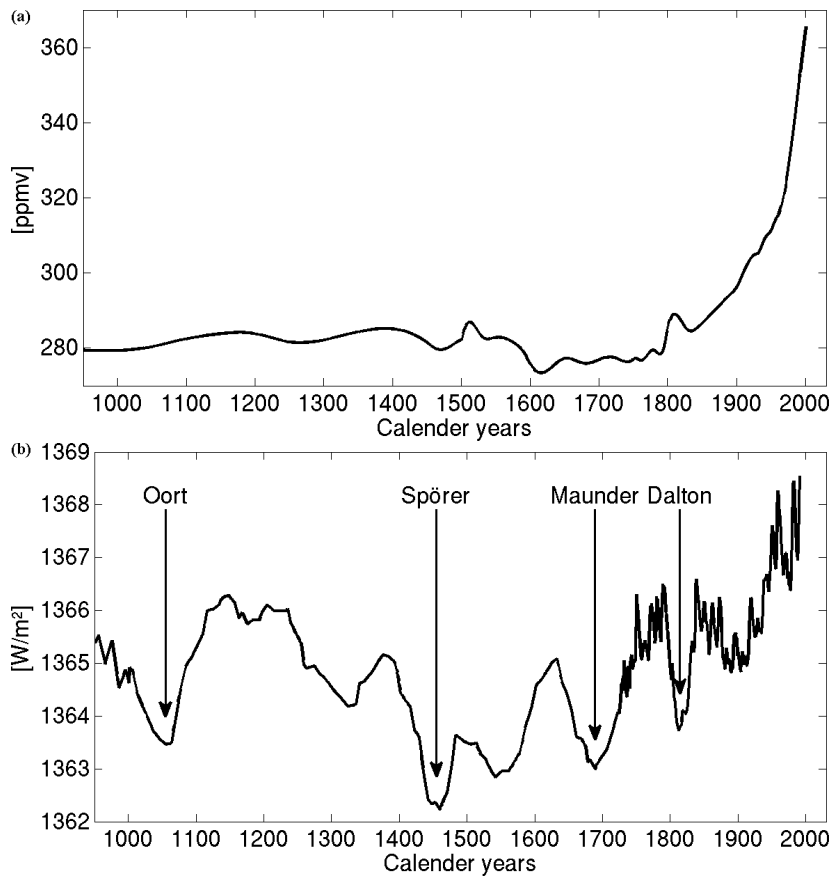

Fig. 2. The main forcing parameters of the simulation. Prescribed $\mathrm{CO}_{2}$ concentrations (ppmv) (a) and solar irradiance $\left(\mathrm{W} \mathrm{m}^{-2}\right)(\mathbf{b})$.

the Maunder, and the Dalton minimum, whereas each minima lasts over several decades (Fig. 2b). The solar variability in the models is scaled to an insolation difference between present day and the Maunder Minimum of $0.3 \%$ (corresponds to $4 \mathrm{~W} \mathrm{~m}^{-2}$ ), as estimated by Lean et al. (1995). Note that this is only one assumption and the discussion on the amplitude of solar variability is still ongoing (cf. Gray et al., 2010). Whereas many recent studies reveal that the amplitude was lower (e.g. only $1.3 \mathrm{~W} \mathrm{~m}^{-2}$ Krivova et al., 2007), another study shows that the amplitude could have been even higher $\left(6 \mathrm{~W} \mathrm{~m}^{-2}\right.$ Shapiro et al., 2011). Besides the uncertainty in the solar forcing it should be mentioned that volcanic forcing is not considered in this experimental setup. However, the role of volcanoes for climate variability is still under discussion.

In a next step, the downscaled atmospheric data are used to force RCO-SCOBI. Four experiments are performed in this study (Table 1). For the MCA as well as for the LIA $100 \mathrm{yr}$ periods are selected with exceptional high and low temperatures according to the RCA simulation (see Sect. 3, Fig. 3). We force RCO-SCOBI with output from RCA for which a bias adjustment had to be applied for temperature and wind speed. Biases arise partly from the large-scale atmospheric circulation in the driving GCM (cf. Kjellström et al., 2011). Further, some biases over the Baltic Sea arise from the prescribed SSTs taken from ECHO-G. The coarse scale of the ocean in the global model leads to a relatively poor representation of the Baltic Sea area. The bias adjustment was made as a change in the mean value by adding (temperature)

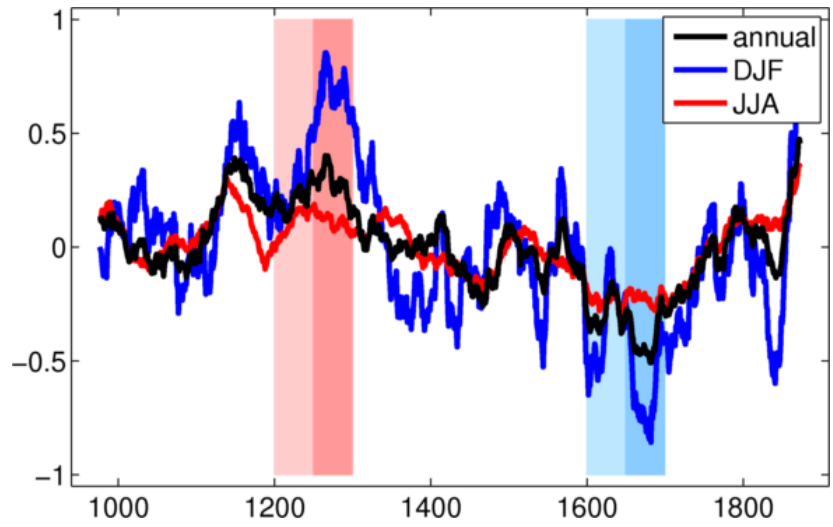

Fig. 3. The 2-m temperature anomaly with regard to the preindustrial mean (950-1900) is illustrated for the winter (DJF), summer (JJA) and annual mean averaged over the Baltic Sea region. The coloured sections highlight the periods that are defined as MCA (red) and LIA (blue) in this study. The darker colours reflect the 50yr periods which are considered for the analysis of the Baltic Sea.

or multiplying (wind speed) spatial variable fields for each month. The correction fields are derived from a comparison with an RCA simulation forced with ERA40 for the period 1961-2008. Table 2 gives an overview over the amplitude of the bias adjustment. Due to the coarse scale in the Baltic Sea of the global model and the interpolation of SSTs from the surrounding oceans, the 2-m temperature is mainly underestimated. The mean bias is considerable larger during summer (up to $3.87 \mathrm{~K}$ in July) where the Baltic Sea becomes warmer than the surrounding ocean. Only during winter months, for some regions a negative bias correction has to be applied (not shown). This is mainly connected to missing sea ice cover and occurs therefore mainly in the northern part of the Baltic Sea. A consequence of the generally underestimated nearsurface temperatures is too strong static stability in the lower atmosphere over the Baltic Sea. Therefore, wind speeds are considerably underestimated, especially during summer and autumn. Here, the wind speed is adjusted by up to $15 \%$, whereas changes in winter and spring are general smaller than $5 \%$. Note that the variability of the forcing parameters remain unchanged by the used bias adjustment.

In addition to the simulations forced directly with the RCA3-data (referred to as RCO-MCA and RCO-LIA), two sensitivity experiments for the MCA were performed. An increase of $2 \mathrm{~K}$ for the 2-m air temperature was implemented constant in time and space to amplify the temperature effect, whereas all other parameters stayed unchanged. Since the total temperature difference compared to the LIA is about $3 \mathrm{~K}$, in this case we refer to this simulation as RCO-3K. In the other experiment higher nitrate and phosphor loads were used (RCO-HL). While all other simulations use nitrate and phosphate concentrations in the river runoff as estimated by Savchuk et al. (2008) for $1850 \mathrm{AD}$, we increase these values by roughly $30 \%$ for RCO-HL. 
Table 1. Overview of performed RCO simulations for the MCA and LIA. The overview includes the simulated periods, the forcing 2-m air temperature anomaly relative to the LIA state $\left(T_{0}\right)$, and the nutrient loads.

\begin{tabular}{lcll}
\hline & Period & Temperature & Nutrient loads \\
\hline RCO-LIA & $1600-1699$ & $T_{0}$ & 1850 level \\
RCO-MCA & $1200-1299$ & $T_{0}+1 \mathrm{~K}$ & 1850 level \\
RCO-3K & $1200-1299$ & $T_{0}+3 \mathrm{~K}$ & 1850 level \\
RCO-HL & $1200-1299$ & $T_{0}+3 \mathrm{~K}$ & 1850 level $+30 \%$ \\
\hline
\end{tabular}

We used estimations of the 1850 state of the Baltic Sea as starting conditions. These are taken from other simulations and establish the best estimation available for the preindustrial time. The same starting field is used for RCOMCA and RCO-LIA. The sensitivity studies are initialised from the RCO-MCA run, more precisely the final state in 1299, to reduce spin-up effects. However, since a spin-up must be assumed for all simulations, we skip the first $50 \mathrm{yr}$ and use only the second half of the simulations.

\section{Results: atmospheric response}

\subsection{Temperature evolution}

Figure 3 illustrates the temporal evolution of the mean temperature in the Baltic Sea area during the pre-industrial period (950-1900 AD) as 50-yr running means. In addition to the annual mean (black), winter (DJF, blue) and summer (JJA, red) temperatures are illustrated as anomalies with regard to the pre-industrial mean. The warmest period appears in the 13th century, whereas the 17th century is the coldest in the simulation (Fig. 3). These centuries are referred to as MCA and LIA in this study and are highlighted in Fig. 3.

The absolute maximum in the Baltic Sea region is reached towards the end of 13th century with a winter temperature anomaly of $0.85 \mathrm{~K}$, whereas the coldest winters are about $0.81 \mathrm{~K}$ colder in the 17 th century than on average (Fig. 3). These values reflect the largest amplitudes within the MCA and LIA centuries, whereas the mean signals covering the entire century are weaker $(+0.41$ and -0.47 , respectively, Table 3). Moreover, the signals are most pronounced during the winter season, whereas the summer months indicate a much weaker difference between the MCA and LIA.

The anomalies in the annual mean are mainly driven by changes in winter temperatures since these have the larger amplitude. For example, the cold peaks in the 17th century are connected to winter anomalies only while there is no clear signal in any other season (Fig. 3). Therefore, the amplitude of annual means is higher than the amplitude for summer means and lower than the amplitude of winter means (Table 3). For 50-yr periods the maximum annual mean temperature difference between the MCA and the LIA is $0.87 \mathrm{~K}$.
The evolution of the temperature anomalies follows for all seasons to some degree the fluctuations in the solar and GHG forcing (cf. Fig. 2). Especially, the high solar irradiation in the 12th and 13th century as well as low irradiation in the Maunder minimum agree well with the temperature evolution. However, as expected, there are differences and all details are not correlated as the local and regional temperature is not identical to the large-scale global and hemispheric evolution. Moreover, the model-generated internal variability is not necessarily in phase with that in the real climate system. Discrepancies include that the lowest insolation appears in the Spörer minimum, whereas the coldest temperature occurs in the Maunder Minimum where on the other hand the GHG concentrations are somewhat lower. Moreover, the evolution of the temperature is characterised by more peaks than the forcing series.

An additional minimum is found around 1810 AD. Here, once more the strongest signal can be found especially for the winter running mean. This minimum seems to be connected with the solar Dalton minimum (Fig. 2b) even if it occurs a little later. Most climate models simulate only a clear Dalton minimum if volcano eruptions are considered (Wagner and Zorita, 2005). However, in the forcing of both ECHO-G and RCA3 volcanoes are not included. Therefore, it cannot be excluded that the signal is to a great extent connected to internal variability in our simulation. On the other hand, it is also possible that small forcings amplify through positive internal feedbacks (e.g. ice albedo feedback) on the regional scale.

The long-term evolution of the temperature climate is in broad agreement with proxy-based reconstructions of the climate (e.g. Ljungqvist et al., 2012) with a warm MCA and a cold LIA. However, details between reconstructions and the model integration differ. An example is the fact that the model simulated maximum is in the 12th and 13th centuries while the reconstructions have this maximum earlier. One reason for this disagreement could be the missing volcanic forcing in the model simulation which effects hemisperic temperatures.

As the internal variability in the model simulation is not in phase with that in the real climate system, we do not perform any direct comparisons with proxy data in detail. Instead, we look at the variability in the model and a proxy-based reconstruction of wintertime temperatures from Stockholm (Leijonhufvud et al., 2010, Fig. 4b). The comparison reveals that the variability in RCA3 is slightly higher on both inter-annual time scales (standard deviation $2.1 \mathrm{~K}$ in RCA3, $1.8 \mathrm{~K}$ in the proxy-record) and longer time scales $(0.64 \mathrm{~K} / 0.43 \mathrm{~K}$ on 30 yr filtered data). Further, in the next section we compare the relation between variables in the model to the same relation in proxy-based reconstructions. 
Table 2. Overview of the monthly applied bias adjustments for temperature [K] and wind speed [a factor]. The values reflect means over the entire RCO model domain but note that the bias adjustment was applied spatially heterogenous.

\begin{tabular}{lrrrrrrrrrrrrr}
\hline & Jan & Feb & Mar & Apr & May & Jun & Jul & Aug & Sep & Oct & Nov & Dec \\
\hline Temperature [K] & -1.87 & -0.45 & -1.73 & -2.49 & -2.96 & -3.34 & -3.87 & -3.54 & -2.12 & -1.73 & -2.25 & -2.79 \\
\hline Wind speed [factor] & 1.02 & 0.96 & 1.00 & 0.97 & 1.01 & 1.09 & 1.15 & 1.14 & 1.11 & 1.11 & 1.10 & 1.05 \\
\hline
\end{tabular}

Table 3. Overview over modelled 2-m air temperature anomalies during the MCA and the LIA with regard to the pre-industrial mean (9501900 AD). The values reflect differences in the Baltic Sea area as indicated in Fig. 1. Anomalies are shown for winter (DJF), summer (JJA), and the annual mean (ann). The rows show values for the entire century, the second half of the century, and the absolute maximum (minimum) for a $50-\mathrm{yr}$ period within the MCA (LIA).

\begin{tabular}{lcccccc}
\hline & MCA DJF & LIA DJF & MCA JJA & LIA JJA & MCA ann & LIA ann \\
\hline Entire century & 0.41 & -0.47 & 0.10 & -0.25 & 0.22 & -0.37 \\
2nd half of the century & 0.60 & -0.78 & 0.07 & -0.24 & 0.23 & -0.47 \\
Abs. max./min. for 50 yr & 0.85 & -0.81 & 0.19 & -0.30 & 0.40 & -0.47 \\
\hline
\end{tabular}

\subsection{The North Atlantic Oscillation}

\subsubsection{NAO-temperature relationship}

The state of the NAO controls the climate of Northern Europe to a large degree (Hurrell, 1995). Especially, the winter temperature in the Baltic Sea area and precipitation in the Norwegian mountains is affected. The positive correlation of the NAO index and winter temperatures in Stockholm in the model is shown in Fig. 4a. Positive NAO phases correspond to positive temperature anomalies in Stockholm, whereas winters with low NAO index have below normal temperatures on average. The highest correlation can be found for 20 -yr running means as shown in Fig. 4a. A similar picture is revealed when proxy-based reconstructions of temperature (Leijonhufvud et al., 2010) and NAO index (Luterbacher et al., 2002) are compared to each other (Fig. 4b). A detailed analysis of the correlation between the two series is performed for the pre-industrial time period 1543-1900. The period is chosen so that a number of years with missing data in the temperature proxy is not included. Before calculating correlation coefficients both temperature and NAO index series are linearly detrended to remove the contribution from any long-term trend to the correlation. The correlation coefficient for RCA3 is 0.52 calculated on an inter-annual basis while the corresponding number is 0.47 for the two proxy series. Applying a 20-yr running mean to the data increases the correlation coefficients to 0.66 in RCA3 and 0.52 in the proxies (Fig. 4). These results indicate that the model has a somewhat stronger dependence on the NAO for the winter time temperatures in Stockholm than that derived by the proxies. This holds true both on inter-annual and decadal time scales, but on even longer time scales, the opposite is the case as the corresponding correlation coefficient reduces to 0.59 in
RCA3 while being higher, 0.68 , in the proxies when a running 30-yr mean filter is applied. The differences in correlation coefficients are, however, not statistically significant making it difficult to draw any conclusions about systematic differences between model and proxies.

Although the results show a relatively strong correlation between the NAO index and the temperature climate in the Baltic Sea region, the NAO index only explains some 25$50 \%$ of the total variability on different time scales. For the remainder other factors as GHG concentrations needs to be taken into account. However, it is evident that internal variability in the model, partly manifested as variations in the NAO index, has a strong influence on the regional and local climate. Thereby, we note that the imposed external forcing (mainly GHG concentrations and solar variability) has large scale effects albeit with large local differences. For the relatively small Baltic Sea region the temperature climate appears to be controlled by a combination of the direct effect of the forcing itself and by internal variability. The latter may be purely a result of internal dynamical processes, or, a result of effects of the changing forcing on for instance the NAO.

\subsubsection{Evolution of the NAO index}

Most proxy and model studies agree that the LIA was characterised by prevailing negative NAO index conditions (e.g. Shindell et al., 2001; Luterbacher et al., 2002; Spangehl et al., 2010). For the MCA, the confidence level is not that high since very few proxy data sets reach that far back in time. In general, proxy based results depend strongly on the applied method which includes a certain amount of uncertainty (e.g. Bürger and Cubasch, 2005) so that results should be compared advisedly. Nevertheless, some reconstructions exist that could be used. Trouet et al. (2009) find evidence that 

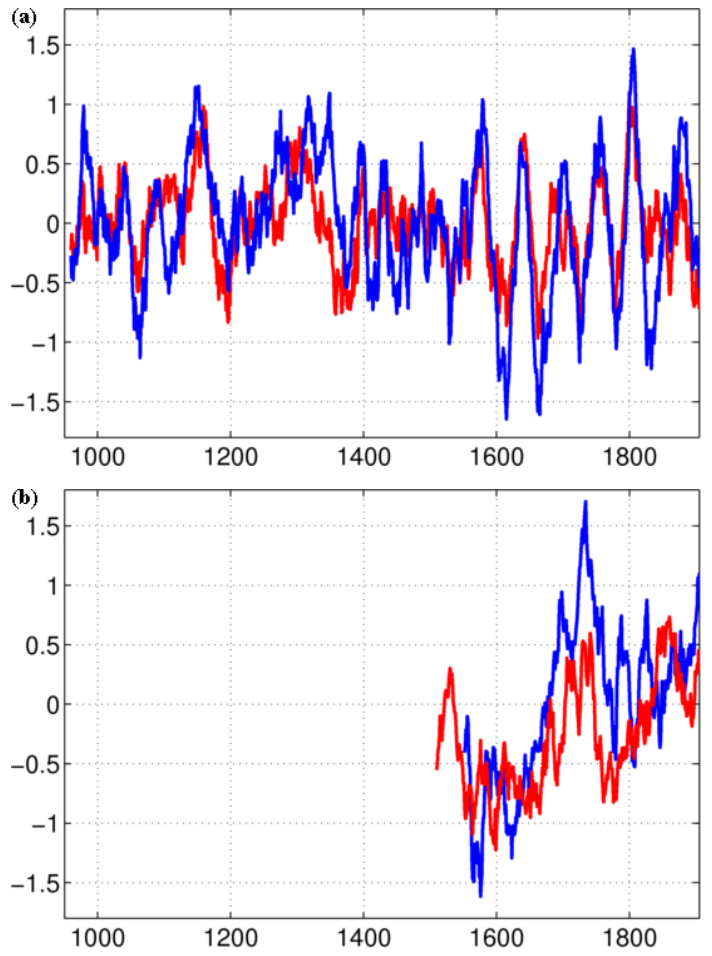

Fig. 4. (a) The simulated NAO index (red) and the 2-m temperature for a grid box representing Stockholm (blue). (b) Proxy-based reconstructions of the NAO-index (Luterbacher et al., 2002) and 2-m temperature in Stockholm (Leijonhufvud et al., 2010). The modelled NAO index is computed according to Hurrell (1995) for DJF whereas the temperature reflects DJFM values for both modelled and reconstructed series. All series are shown as 20-yr running means.

the phase with the highest NAO index during the last millennium appeared during the MCA (Fig. 5). According to this study more than two centuries (12th and 13th) were characterised by an exceptional high winter NAO index. Even if the mean state of the NAO index is positive during the MCA, in our simulation a comparable strong and robust signal as in that particular proxy-based record is not reproduced. Two periods with very high simulated NAO indices occur within the MCA, namely towards the end of the 12th century and around $1300 \mathrm{AD}$ (Fig. 4). Nevertheless, these two maxima are separated by a deep minimum with a negative NAO index situation, a feature that is absent in the Trouet et al. (2009) proxy data until the 15 th century. Here, it should be noted that these large scale circulation features in the RCM are steered mainly by the driving GCM. The RCA model domain is too small to differ considerably from ECHO-G in the NAO phase. That ECHO-G is not reproducing the positive NAO phase is in-line with other model studies of the MCA (Mann et al., 2009; Jungclaus et al., 2010). Reasons for that are widespread and reach from a missing signal in the Pacific where a strong La Niña like pattern was prevailing influencing Europe via teleconnections (Mann et al., 2009) to the lack

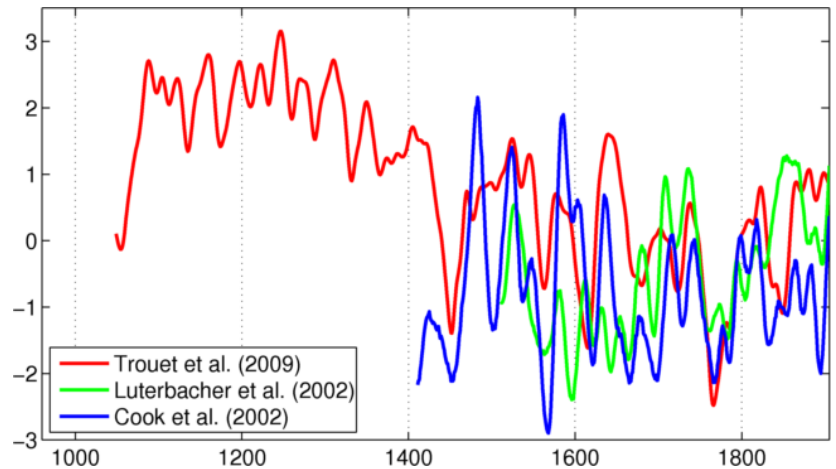

Fig. 5. The winter NAO index for proxy data (Cook et al., 2002; Luterbacher et al., 2002; Trouet et al., 2009). All time series are low-pass filtered with a cut-off frequency of $30 \mathrm{yr}$ and normalised thereafter

of a fully resolved stratosphere which can modify the solar signal response down to the surface (e.g. Gray et al., 2010). Moreover, as discussed above, an absolute match cannot be expected since the development of the NAO index comprises to a large degree internal variability which is supposed to be independent from the external forcing. Therefore, an overall agreement of proxy data and model results cannot be requested.

After 1500 AD more proxy series of the NAO index exist. The data of Luterbacher et al. (2002) and Cook et al. (2002) are included in Fig. 5 to demonstrate the uncertainties related to proxy data. Gómez-Navarro et al. (2011) discussed already for the Luterbacher et al. (2002) and Trouet et al. (2009) data that there is no agreement in general. Partly, similar signatures can be found as for instance the minimum before 1800 which is also shown by the Cook et al. (2002) data. However, large parts are less correlated. While the Luterbacher et al. (2002) data show a distinct minimum during the LIA without any strong positive anomalies, the other series include several maxima with positive anomalies. Obviously, there are large uncertainties included in the proxy data and its interpretation as recently demonstrated by Lehner et al. (2012) for the Trouet et al. data. Therefore, it remains an open question if the NAO index was that high and constant during the MCA as indicated by Trouet et al..

\subsection{Runoff and precipitation}

The runoff is estimated from the net water budget (precipitation minus evaporation) over the Baltic Sea drainage area using a statistical model (see Meier et al., 2012a for more information). It is illustrated in Fig. 6 in combination with precipitation averaged over the catchment area. The 50-yr running means of the two variables show considerable multi-decadal variability in a close relationship. The correlation coefficient of both $50-\mathrm{yr}$ running means is 0.68 , whereas the correlation coefficient for annual values is 0.66 . 


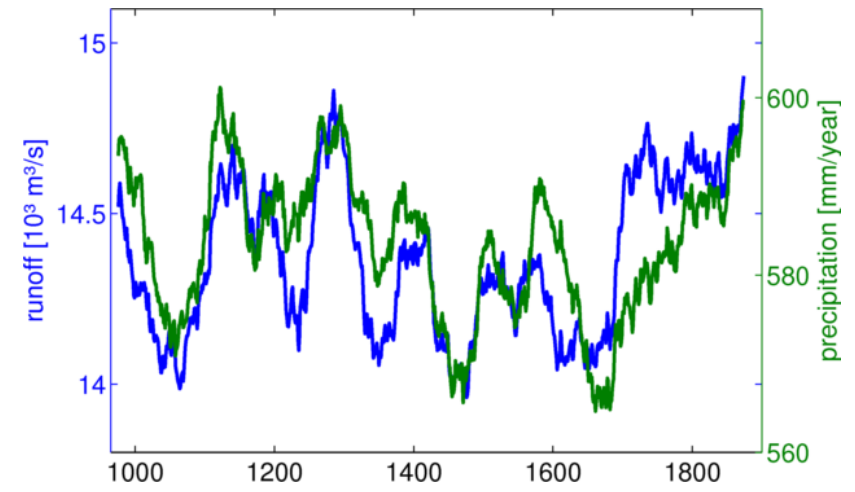

Fig. 6. Precipitation in the Baltic Sea catchment area (green, see Fig. 1) and statistical estimated runoff (blue) as 50-yr running means.

Runoff and precipitation are considerably larger during the MCA than the LIA. The 50-yr peak runoff during the MCA is approximately $800 \mathrm{~m}^{3} \mathrm{~s}^{-1}(+6 \%)$ higher than in the LIA (Fig. 6). Moreover, the mean values for the runoff over the full 100-yr periods $(+2.4 \%)$ and the last $50 \mathrm{yr}(+3.8 \%)$ also differ considerably between the MCA and the LIA. The results here, with more precipitation during the MCA compared to the LIA, is in general agreement with the findings in Graham et al. (2009), although a detailed comparison is difficult to make as they are only focusing on the northerly drainage basins of the Baltic Sea area. Moreover, the fluctuations in precipitation are in agreement with modelled changes in the NAO index since the largest positive precipitation anomalies occur during winter, whereas there is no significant difference during summer months (not shown).

\subsection{Spatial anomaly pattern}

As mentioned above, most proxy and model studies indicate warm and cold anomalies as the MCA and LIA are connected with high or low NAO index situations - at least during winter. We derive from our simulation that the variability of the NAO contributes especially to the extremes on the multi decadal time scale, whereas other parameters have an effect on even longer time scales (Sect. 3.1). Consistently, the SLP difference between the full MCA and LIA shows a rather weak positive NAO pattern which is mainly characterised by lower pressure in the north (Fig. 7). The pressure gradient between Iceland and Portugal is weaker by more than $1 \mathrm{hPa}$.

The pattern becomes much stronger for the 50 -yr periods. A clear positive NAO anomaly is simulated for the MCA in comparison to the LIA. In contrast to the usual NAO signature observed in the late 20th century, which shows the strongest SLP reduction over Iceland (e.g. Hurrell, 1995), the simulated signal is shifted towards Northern Scandinavia. Nevertheless, the north-south pressure gradient is stronger all over Europe and by more than $2.75 \mathrm{hPa}$ between Iceland and Portugal. A positive NAO pattern predominate also during autumn though with a reduced amplitude. The differences are negligible in summer and spring (not shown).

Since we defined our MCA and LIA periods by warm and cold phases in the running mean (Fig. 3) we see a clear signal in the spatial pattern of the temperature differences. In correspondence to stronger winter amplitudes in the running mean we find the largest differences in the spatial winter pattern (Fig. 7). The temperature difference increases from $0.5 \mathrm{~K}$ at the southern tip of the Baltic Sea to more than $1.5 \mathrm{~K}$ in Northern Fennoscandia for the full 100 -yr periods. While smaller differences exist for spring and autumn there is almost none in summer (not shown).

For the 50-yr periods the winter mean temperatures over Scandinavia differ between 1 and $2.5 \mathrm{~K}$ over Fennoscandia (Fig. 7). The amplitude increases from the southwest towards the northeast. For the shorter period an increase can be seen also during summer (roughly $0.4 \mathrm{~K}$, not shown).

Since the differences in the SLP patterns are only minor for the full periods large signals cannot be expected for the $10 \mathrm{~m}$ wind speed. A slight increase is found for the MCA with local maxima of $0.2 \mathrm{~m} \mathrm{~s}^{-1}$ over the Baltic Sea (Fig. 7). Compared to the mean wind speed of $5-7 \mathrm{~m} \mathrm{~s}^{-1}$ that change is not much.

The signal is stronger over the Southern Baltic Sea for the 50-yr periods in line with the higher NAO index. The mean wind speed is enhanced by more than $0.2 \mathrm{~m} \mathrm{~s}^{-1}$ in large areas and by up to $0.4 \mathrm{~m} \mathrm{~s}^{-1}$ over the Southern Baltic proper. A similar pattern is prevailing for the gustiness but with a higher amplitude (more than $0.5 \mathrm{~m} \mathrm{~s}^{-1}$, not shown). These differences are in line with the SLP signatures. Moreover, changes in the SLP field assume that the westerly component is mainly strengthened during the MCA.

Finally, 2-m temperature patterns are shown for the global model ECHO-G (right column of Fig. 7). The coarse resolution and therefore the missing relation to real land-sea surface differences are obvious when compared to the temperature response of RCA. This effect is clearest along the Norwegian coast line for the 50-yr periods. Here, RCA simulates a very sharp temperature anomaly gradient from the Atlantic towards land points over Scandinavia. On the other hand, such a clear signal cannot be simulated in ECHO-G. However, the general amplitude is very comparable for RCA and ECHO-G with somewhat stronger signals in ECHO-G over the most eastern land areas. Overall, the contrast between the patterns of RCA and ECHO-G clearly highlights some of the added value of the dynamical downscaling approach.

\section{Results: Baltic Sea response}

\subsection{Evolution of water temperature, sea ice and salinity}

The atmospheric data of the 13 th and 17 th century are then used to simulate the behaviour of the Baltic Sea in the MCA 

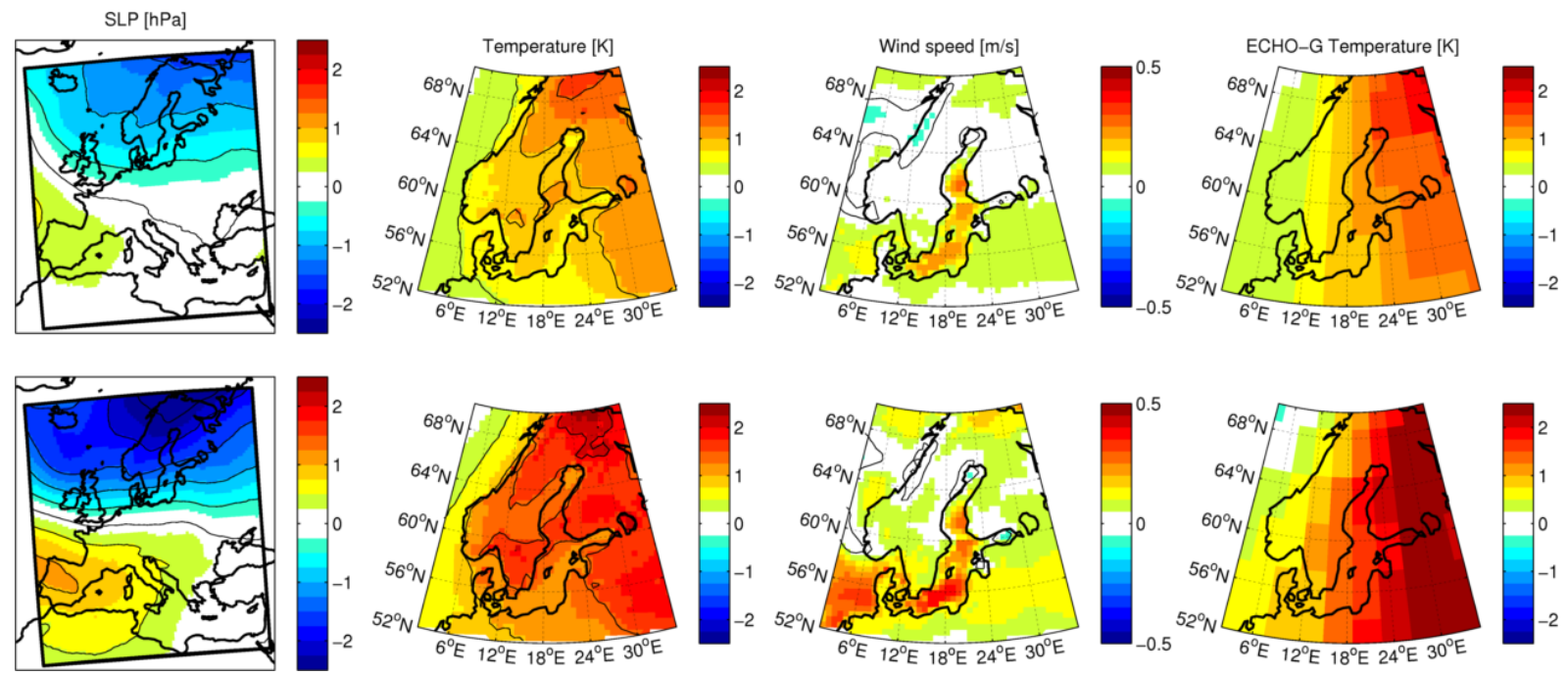

Fig. 7. SLP, temperature and wind speed differences between the 100-yr (top panel) and the 50-yr (bottom panel) periods of the MCA and LIA (as indicated in Fig. 3a) are shown. The right column shows 2-m temperature differences for the global model ECHO-G, whereas the others show differences for the RCA simulation. All variables show winter (DJF) means.

and the LIA, respectively. Box plots are shown for temperature, salinity and maximum ice cover in Fig. 8 for both extreme periods for the last $50 \mathrm{yr}$.

As a consequence of the atmospheric boundary conditions, the volume averaged temperature of the Baltic Sea is higher during the MCA than during the LIA. The mean difference adds up to $0.50 \mathrm{~K}$ which is less than the averaged air temperature signal over the Baltic Sea $(0.73 \mathrm{~K})$. The annual variability is that high that some years out of the MCA are colder than warm years of the LIA.

The mean maximum ice cover is somewhat smaller during the MCA than in a run forced with ERA40 at the boundary (Table 4). This is reasonable since the MCA is supposed to be approximately as warm as the recent warm period (Ljungqvist et al., 2012). The ice cover is higher during the LIA. The mean difference between the MCA and the LIA is about $44000 \mathrm{~km}^{2}$.

In comparison with observations collected by the Finnish Meteorological Institute (Seinä and Palosuo, 1993) two differences are evident. First, the present model setup seems to underestimate the maximum annual ice cover by more than $20000 \mathrm{~km}^{2}$. Second, the long-term variability within the observational data is larger than the difference between the modelled MCA and LIA when 50-yr periods are considered for the observations and the simulations. This adds further evidence that the simulated temperature difference between the MCA and LIA is underestimated.

The mean difference in volume averaged salinity between RCO-MCA and RCO-LIA is 0.69 PSU (Fig. 8c). This is an effect of both the increased runoff (Fig. 6) and the stronger westerlies (Fig. 7). First, the increased runoff dilutes the Baltic Sea surface water. Then, due to internal recycling saltwater inflows are diluted as well, which reduces the amount
Table 4. Mean annual maximum sea ice extent $\left(10^{3} \mathrm{~km}^{2}\right)$ modelled for RCO-LIA, RCO-MCA, RCO-3K and a simulation forced with ERA40 boundary conditions (1961-2000). In addition, observed maximum sea ice cover for the period 1720-2000 is presented (Seinä and Palosuo, 1993). Here, we show the absolute minimum (1902-1951) and maximum (1766-1815) over 50 succeeding years as well as the mean over the period 1961-2000.

\begin{tabular}{ccccc}
\hline \multirow{2}{*}{ Model results } & RCO-MCA & RCO-LIA & RCO-3K & ERA40 \\
& 149 & 193 & 96 & 162 \\
\hline \multirow{2}{*}{ Observations } & $1902-1951$ & $1766-1815$ & & $1961-2000$ \\
& 182 & 264 & & 185 \\
\hline
\end{tabular}

of salt entering the Baltic Sea (Meier, 2005). The increase of wind speed deepens the mixing layer which leads to a dilution of inflowing salt water, too. In addition, the increase of the mean westerly wind speed causes anomalous high sea levels in the Baltic Sea. This produces a barotropic pressure gradient and hampers the flow of high-saline water through the Danish Straits into the Baltic proper (Meier and Kauker, 2003). A similar long-term sensitivity for stronger westerly winds for the Baltic Sea was shown by Zorita and Laine (2000).

\subsection{Vertical profiles in the Gotland Deep}

In this section, vertical profiles at the Gotland Deep are investigated (Fig. 1). This location lies in the middle of the Baltic Sea and is representative for large parts of it. For instance, due to the strong stratification the bottom layers are poorly ventilated, and only strong major inflows of salty water from the North Sea renew this bottom water intermittently. 

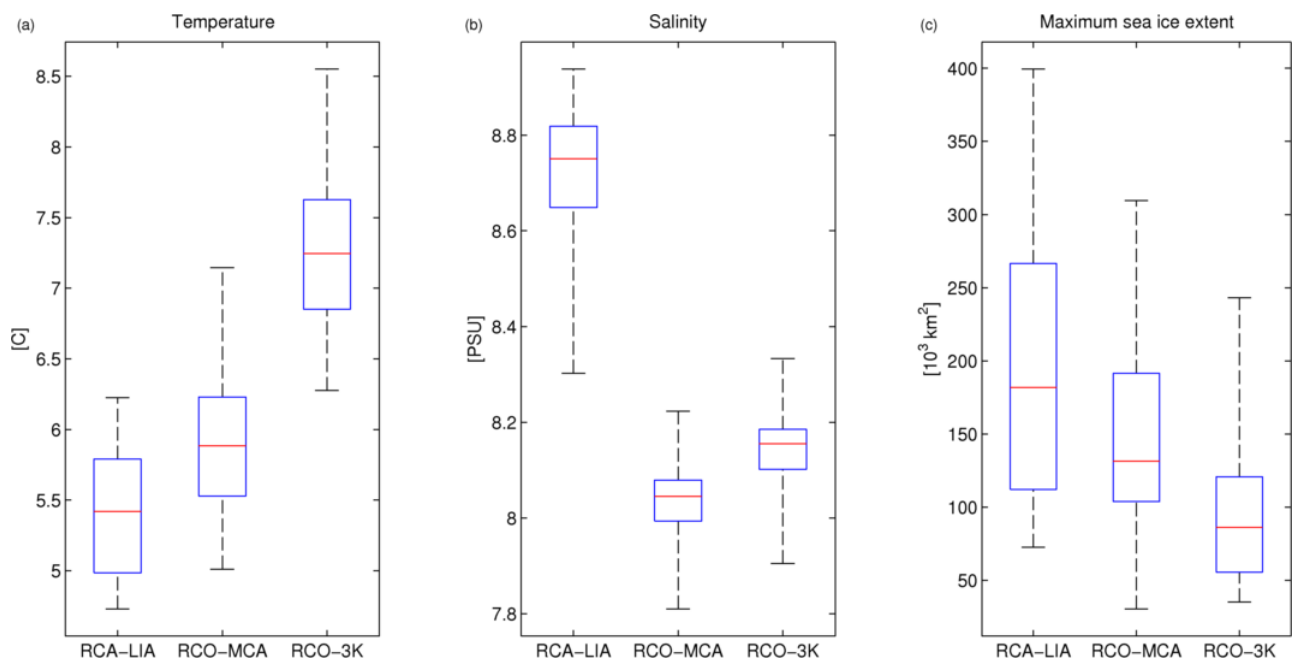

Fig. 8. Whisker plots of volume averaged annual mean temperature (a), volume averaged annual mean salinity (b), and maximum sea ice extent (c). Each panel includes values of RCO-LIA, RCO-MCA, and RCO-3K. The red line marks the median, the edges of the blue box are the 25th and 75th percentiles, the whiskers extend to the most extreme data points.

Temperature differences between RCO-MCA and RCOLIA are quite uniform over the entire water column and amount to $0.5 \mathrm{~K}$ in the mean. The differences are larger in the mixed layer down to $50 \mathrm{~m}(0.68 \mathrm{~K})$ and somewhat smaller around $60 \mathrm{~m}(0.29 \mathrm{~K})$, whereas the deep layers warm by about $0.5 \mathrm{~K}$ (Fig. 9a).

Salinity reductions amount to $0.59 \mathrm{PSU}$ at the surface and 0.78 PSU in the layers below the halocline. The largest decrease appears in the halocline with a reduction of more than 1 PSU. This implies in combination with the temperature response that the mixed layer is deeper in the MCA than in the LIA. This is in line with results of future projections, where the Baltic Sea becomes warmer and fresher as well (Meier et al., 2011a).

The oxygen profiles show the typical behaviour with high and saturated concentrations close to the surface and lower concentrations in deeper layers. Compared to observations the concentrations are higher in the deep layers and neither anoxic nor hypoxic conditions occur in the MCA or the LIA. Nevertheless, some differences can be identified between the two periods. First, a small reduction of oxygen concentrations $\left(-0.1 \mathrm{ml}^{-1}\right)$ can be seen in the mixed layer. This is determined by higher temperatures and reflects the reduction of the saturation level. Second, a slight increase $\left(+0.3 \mathrm{ml} \mathrm{l}^{-1}\right)$ is present around $60 \mathrm{~m}$ depth which reflects the deepening of the mixed layer which brings higher oxygen concentrations into deeper waters. Finally, oxygen concentrations are slightly reduced in the bottom water in the MCA compared to the LIA. Maximum decrease is found close to the bottom with a reduction of $0.5 \mathrm{ml} \mathrm{l}^{-1}$.

\subsection{Sensitivity studies}

Proxy studies suggest that temperature differences between the MCA and LIA have been stronger than simulated in our model setup. That is shown for reconstructed 2-m air temperature (e.g. Leijonhufvud et al., 2010) as well as SSTs (Kabel et al., 2012). Hence, a sensitivity experiment is performed with $2 \mathrm{~K}$ higher air temperatures compared to RCO-MCA.

The first order effect is an increase of $1.3 \mathrm{~K}$ in the volume averaged temperature compared to RCO-MCA (Fig. 8a). This difference is constant over the entire simulation, whereby the annual variability is the same in RCO-MCA and RCO-3K. The difference between MCA-3K and RCOLIA adds up to $1.84 \mathrm{~K}$ for the volume averaged temperature of the Baltic Sea. The vertical temperature profile at Gotland Deep reveals a similar behaviour for RCO-MCA and RCO$3 \mathrm{~K}$ only with higher amplitudes for RCO-3K. For instance, the difference in SST in comparison with RCO-LIA is enhanced to more than $2 \mathrm{~K}$ what is in agreement with reconstructed differences between the MCA and the LIA (Kabel et al., 2012). Moreover, a minimum is still existing around $60 \mathrm{~m}$ depth.

The mean maximum sea ice cover is strongly reduced and amounts to less than $100000 \mathrm{~km}^{2}$ in RCO-3K. However, an ice cover exists during all winters with a minimum extension of $24500 \mathrm{~km}^{2}$ (Fig. 8c). Salinities are somewhat higher (+0.1 PSU) in RCO-3K than in RCO-MCA, whereby the annual variability is very similar in both simulations (Fig. 8b). The main reason for this is likely a higher evaporation due to higher temperatures. However, a long lasting effect of the different starting points cannot be excluded completely. The absolute salinity difference to RCO-LIA is still a reduction but less pronounced ( $-0.58 \mathrm{PSU})$. The shape of anomalies in 

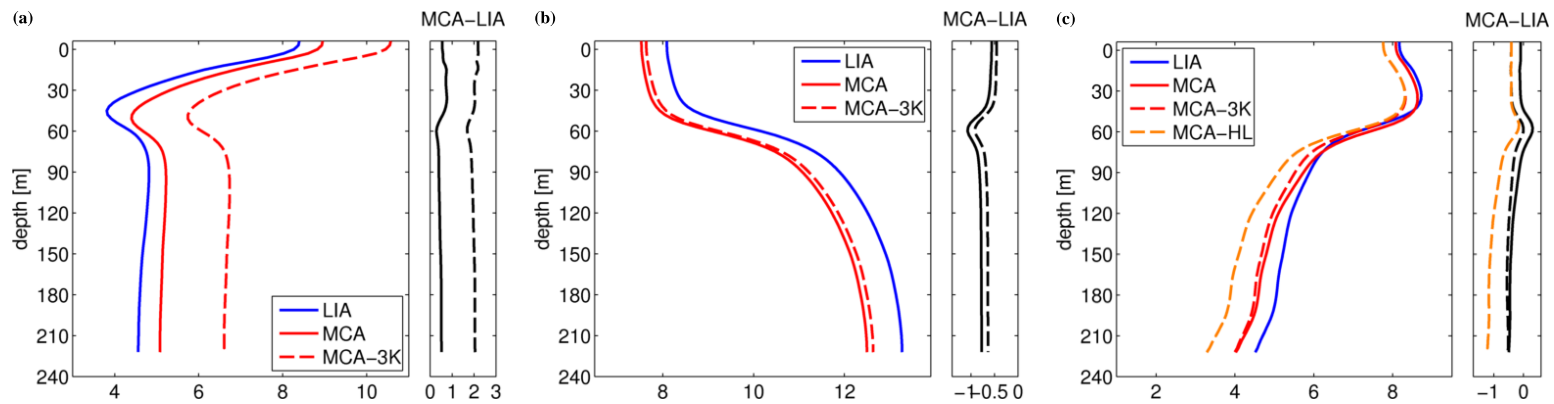

Fig. 9. Vertical profiles at Gotland Deep (location see Fig. 1). Solid lines show the profiles for RCO-MCA (red) and RCO-LIA (blue) while the dashed lines represent results from RCO-3K (red) and RCO-HL (orange), respectively. On the right sides, deviations from RCO-LIA are illustrated. Profiles are shown for temperature (a), salinity (b), and oxygen concentrations (c) and reflect means over the last $50 \mathrm{yr}$ of the simulations.

the vertical profile is comparable to the RCO-MCA-RCOLIA differences.

The oxygen profile for RCO-3K indicates a clear reduction for the mixed layer oxygen concentrations. The reduction by roughly $0.4 \mathrm{ml} \mathrm{l}^{-1}$ reflects the effect of reduced saturation levels due to higher temperatures. The signal is clearly emphasised in comparison to RCO-MCA. However, the difference to RCO-MCA becomes smaller with increasing depths and there is hardly any difference left in the bottom layers.

In addition to studies reporting on higher temperature differences between the MCA and the LIA other studies report on higher nutrient loads during the MCA mainly caused by the heyday of the surrounding population and their agriculture (Zillén et al., 2008). This motivates another sensitivity experiments with higher loads (RCO-HL) while the residual forcing is the same as in RCO-3K.

Since nutrient loads do not have distinct feedbacks on the physics, the response in, for example, temperature and salinity is not different from MCA-3K. Therefore, the medians and quantiles (Fig. 8) as well as the profiles (Fig. 9a,b) are identical in both sensitivity experiments for these variables. The major influence of increased nutrient loads is on the oxygen concentrations in the deep layers (Fig. 9c). Whereas the oxygen concentrations in the mixed layer are the same for both sensitivity experiments, it is obvious that higher loads increase the oxygen consumption in deeper layers. The mean oxygen concentration in the bottom layer of the Gotland Deep is $3.3 \mathrm{ml} \mathrm{l}^{-1}$ in comparison to $4.5 \mathrm{ml} \mathrm{l}^{-1}$ in RCOLIA and $4.0 \mathrm{ml}^{-1}$ in RCO-MCA and RCO-3K, respectively. Therefore, mean oxygen concentrations are considerably reduced in RCO-HL but the model does not simulate hypoxic or anoxic conditions.

\section{Discussion and conclusions}

For the first time a dynamical downscaling approach has been performed for the complete last millennium over Northern Europe. This is so far a unique approach to highlight regional features in the context of natural climate variability. Moreover, the high resolution of the downscaled atmospheric data opens the possibility to perform the first simulations with a dynamical regional ocean model for the Baltic Sea covering the MCA. We demonstrate that the atmospheric model setup of ECHO-G and RCA3 produces a relative warm period in the early centuries of the millennium and cold conditions in the 17th century which is in general agreement with reconstructions (Ljungqvist et al., 2012) and other model studies (e.g. Mann et al., 2009). While most of the long-term change is driven by the external forcing, changes on shorter periods (up to few decades) are connected to internal variability, including anomalies in the NAO index. Neither the external forcing nor the signal in the NAO index can explain the temporal evolution of the temperature independently. Herewith, both amplitude and timing of the modelled MCA and LIA are considerably affected by multi-decadal variability. Pronounced temperature anomalies on century-long time scales are not simulated. This is in agreement with the results of other model studies (Mann et al., 2009; Jungclaus et al., 2010). The temperature differences between the simulated warmest and coldest 50-yr periods are rather small especially for the summer if compared to proxy indicated signals (Ljungqvist et al., 2012), while the variability in winter is as high, or even higher than that retrieved from a proxy-based reconstruction of Stockholm temperatures. The low variability in summer could be a result of the missing volcanic forcing. There is indication from model studies that the inclusion of volcanic eruptions strengthens the agreement with proxy data (Wagner and Zorita, 2005; Jungclaus et al., 2010). Further, the use of SSTs from the GCM simulation for the Baltic Sea can dampen the temperature signals considerable.

Moreover, also in broad agreement to proxy-based reconstructions, our simulation shows that a positive NAO phase was prevailing during the MCA (Mann et al., 2009), whereas the LIA was characterized by a negative NAO phase (Spangehl et al., 2010). However, at least the signal for the MCA is weaker and not as consistent as reconstructed (Trouet et al., 2009). As elucidated in the result section, it 
remains unclear to what extent this is a missing signal in the model setup or the results from the proxy data are overrated. Nevertheless, we demonstrate that the difference in the NAO phase contributes to the positive winter temperature anomaly during the MCA as well as higher westerly wind speed and more precipitation. As a result, the Baltic Sea becomes fresher in RCO-MCA similar to future scenario studies (Meier et al., 2011b). Oxygen concentrations are only slightly effected and show a reduction in the mixed layer and below the halocline, whereas they increase in the range of the halocline owing to the enlarged mixing depth. The sensitivity experiments point out that the reduction in the deep layers is not initiated by higher temperatures, but are sensitive to the amount of nutrient loads. As only the nutrient load concentrations are kept constant, the higher runoff leads in total to a raise of the loads in RCO-MCA. Moreover, higher temperatures in MCA-3K do not have any specific effect on bottom oxygen concentrations. On the other hand, we find a stronger reduction of oxygen concentrations in the sensitivity experiment RCO-HL. Here, the oxygen concentrations are reduced by $1.3 \mathrm{ml}^{-1}$ compared to RCO-LIA. Herewith, our results are in contrast to the findings of Kabel et al. (2012) which show evidence that bottom oxygen conditions depend more on SSTs than on nutrient loads. However, Kabel et al. do sensitivity studies only for the LIA and do not show that higher SSTs are sufficient to create anoxia during the MCA.

Moreover, additional effects besides nutrient loads and SSTs should be considered. For instance, changes in stratification have an impact on oxygen concentrations in the deep. Oxygen conditions improve in the deep due to a better ventilation initiated by reduced salinity (Hansson and Gustafsson, 2011) or higher wind speed (Meier et al., 2012a). These factors counteract the oxygen reduction in RCO-MCA and in our sensitivity studies. Another source for oxygen rich water for the deep layers is inflowing water from the North Sea (Matthäus and Franck, 1992). However, there is no indication in our simulations that the frequency of major inflows differs between RCO-MCA and RCO-LIA. Other effects as discussed for scenario simulations, for instance increased decomposition/oxidation rates of organic matter due to higher temperature (Meier et al., 2011a), are not relevant because the pools are empty according to the low loads.

Anyway, the reduction of bottom oxygen concentrations does not lead to a spread of hypoxia or anoxia during the MCA in the model as it is found in sediment studies (Zillén and Conley, 2010). In fact, the oxygen conditions are simply to high to develop any hypoxia. This holds true also for the sensitivity study with $30 \%$ higher nutrient loads which is perhaps a rather high estimation taking the size of the medieval population into account.

Therefore, further investigations are needed to explain the reconstructed increase of hypoxia during the MCA. Basically, three shortcomings of this study have been identified. Improved atmospheric forcing conditions including the feedbacks from volcanic activity could be crucial. Moreover, estimations of the nutrient supply during the MCA would be helpful (Zillén and Conley, 2010). Finally, potential shortcomings in the parametrisation of oxygen consumption in the bottom layers under nutrient-poor conditions have to be improved as discussed also by Gustafsson et al. (2012) and Meier et al. (2012b). Up to now, the uncertainty is rather high for oxygen concentrations under oligotrophic conditions in state-of-the-art biogeochemical models.

Acknowledgements. The research presented in this study is part of the project INFLOW (Holocene saline water inflow changes into the Baltic Sea, ecosystem responses and future scenarios) and has received funding from the European Community's Seventh Framework Programme (FP/2007-2013) under grant agreement no. 217246 made with BONUS, the joint Baltic Sea research and development programme, and from the Swedish Research Council for Environment, Agricultural Sciences and Spatial Planning (FORMAS, ref. no. 2008-1885). The RCO-SCOBI model simulations were partly performed on the climate computing resources "Ekman" and "Vagn" that are operated by the National Supercomputer Centre (NSC) at Linköping University and the Centre for High Performance Computing (PDC) at the Royal Institute of Technology in Stockholm, respectively. These computing resources are funded by a grant from the Knut and Alice Wallenberg Foundation. We are grateful to Eduardo Zorita for providing the boundary data from the ECHO-G model.

Edited by: V. Rath

\section{References}

Bürger, G. and Cubasch, U.: Are multiproxy climate reconstructions robust?, Geophys. Res. Lett, 32, L23711, doi:10.1029/2005GL024155, 2005.

Conley, D. J., Björck, S., Bonsdorff, E., Carstensen, J., Destouni, G., Gustafsson, B. G., Hietanen, S., Kortekaas, M., Kuosa, H., Markus Meier, H. E., Müller-Karulis, B., Nordberg, K., Norkko, A., Nurnberg, G., Pitkanen, H., Rabalais, N. N., Rosenberg, R., Savchuk, O. P., Slomp, C. P., Voss, M., Wulff, F., and Zillén, L.: Hypoxia-related processes in the Baltic Sea, Environ. Sci. Technol., 43, 3412-3420, doi:10.1021/es802762a, 2009.

Cook, E. R., D'Arrigo, R. D., and Mann, M. E.: A well-verified, multiproxy reconstruction of the winter North Atlantic oscillation index since AD 1400, J. Climate, 15, 1754-1764, 2002.

Eilola, K., Meier, H. M., and Almroth, E.: On the dynamics of oxygen, phosphorus and cyanobacteria in the Baltic Sea; A model study, J. Marine Syst., 75, 163-184, doi:10.1016/j.jmarsys.2008.08.009, 2009.

Eilola, K., Gustafsson, B., Kuznetsov, I., Meier, H., Neumann, T., and Savchuk, O.: Evaluation of biogeochemical cycles in an ensemble of three state-of-the-art numerical models of the Baltic Sea, J. Marine Syst., 88, 267-284, doi:10.1016/j.jmarsys.2011.05.004, 2011.

Gómez-Navarro, J. J., Montávez, J. P., Jerez, S., Jiménez-Guerrero, P., Lorente-Plazas, R., González-Rouco, J. F., and Zorita, E.: A regional climate simulation over the Iberian Peninsula for the last 
millennium, Clim. Past, 7, 451-472, doi:10.5194/cp-7-451-2011, 2011.

Gouirand, I., Moberg, A., and Zorita, E.: Climate variablility in Scandinavia for the past millenium simulated by an atmosphereocean general circulation model, Tellus A, 59, 30-49, 2007.

Graham, L. P., Olsson, J., Kjellström, E., Rosberg, J., Hellström, S.S., and Berndtsson, R.: Simulating river flow to the Baltic Sea from climate simulations over the past millennium, Boreal Environ. Res., 14, 173-182, 2009.

Gray, L. J., Beer, J., Geller, M., Haigh, J. D., Lockwood, M., Matthes, K., Cubasch, U., Fleitmann, D., Harrison, G., Hood, L., Luterbacher, J., Meehl, G. A., Shindell, D., van Geel, B., and White, W.: Solar influence on climate, Rev. Geophys., 48, RG4001, doi:10.1029/2009RG000282, 2010.

Guiot, J., Christophe, C., and ESCARSEL members: Growing season temperatures in Europe and climate forcings over the past $1400 \mathrm{yr}$, PLoS ONE, 5, e9972, doi:10.1371/journal.pone.0009972, 2010.

Gustafsson, B. G., Schenk, F., Blenckner, T., Eilola, K., Meier, H., Müller-Karulis, B., Neumann, T., Ruoho-Airola, T., Savchuck, O., and Zorita, E.: Reconstructing the development of the Baltic Sea eutrophication 1850-2006, AMBIO, 41, 534-548, doi:10.1007/s13280-012-0318-x, 2012.

Haigh, J.: The impact of solar variability on climate, Science, 272, 981-984, 1996.

Hansson, D. and Gustafsson, E.: Salinity and hypoxia in the Baltic Sea since AD 1500, J. Geophys. Res., 116, C03027, doi:10.1029/2010JC006676, 2011.

Helama, S., Meriläinen, J., and Tuomenvirta, H.: Multicentinnial megadrought in Northern Europe coincided with a global El Niño-Southern Oscillation drought pattern during the Medieval Climate Anomaly, Geology, 37, 175-178, doi:10.1130/G25329A.1, 2009.

Hünicke, B., Zorita, E., and Haeseler, S.: Baltic Holocene climate and regional sea-level change: a statistical analysis of observations, reconstructions and simulations within present and past analogues for future changes, Final report of the DFG research unit SINCOS-2, GKSS, Geesthacht, Germany, 2010.

Hurrell, J. W.: Decadal trends in the North Atlantic oscillation: regional temperatures and precipitation, Science, 269, 676-679, doi:10.1126/science.269.5224.676, 1995.

Jönsson, K. and Nilsson, C.: Scots Pine (pinus sylvestris L.) on shingle fields: a dendrochronologic reconstruction of early summer precipitation in Mideast Sweden, J. Climate, 22, 4710-4722, doi:10.1175/2009JCLI2401.1, 2009.

Jungclaus, J. H., Lorenz, S. J., Timmreck, C., Reick, C. H., Brovkin, V., Six, K., Segschneider, J., Giorgetta, M. A., Crowley, T. J., Pongratz, J., Krivova, N. A., Vieira, L. E., Solanki, S. K., Klocke, D., Botzet, M., Esch, M., Gayler, V., Haak, H., Raddatz, T. J., Roeckner, E., Schnur, R., Widmann, H., Claussen, M., Stevens, B., and Marotzke, J.: Climate and carbon-cycle variability over the last millennium, Clim. Past, 6, 723-737, doi:10.5194/cp-6723-2010, 2010.

Kabel, K., Moros, M., Porsche, C., Neumann, T., Adolphi, F., Andersen, T. J., Siegel, H., Gerth, M., Leipe, T., Jansen, E., and Damsté, J. S. S.: Impact of climate change on the Baltic Sea ecosystem over the past 1,000 years, Nature Clim. Change, online first: doi:10.1038/NCLIMATE1595, 2012.
Kaspar, F., Spangehl, T., and Cubasch, U.: Northern hemisphere winter storm tracks of the Eemian interglacial and the last glacial inception, Clim. Past, 3, 181-192, doi:10.5194/cp-3-181-2007, 2007.

Kauker, F. and Meier, H. E. M.: Modeling decadal variablility of the Baltic Sea: 1. Reconstructing atmospheric surface data for the period 1902-1998, J. Geophys. Res., 108, 3267, doi:10.1029/2003JC001797, 2003.

Killworth, P. D., Stainforth, D., Webb, D. J., and Paterson, S. M.: The development of a free-surface Bryan-Cox-Semtner ocean model, J. Phys. Oceanogr., 21, 1333-1348, 1991.

Kjellström, E., Brandefelt, J., Näslund, J.-O., Smith, B., Strandberg, G., Voelker, A. H. L., and Wohlfarth, B.: Simulated climate conditions in Europe during the Marine Isotope Stage 3 stadial, Boreas, 39, 436-546, doi:10.1111/j.1502-3885.2010.00143.x, 2010.

Kjellström, E., Nikulin, G., Hansson, U., Strandberg, G., and Ullerstig, A.: 21st century changes in the European climate: uncertainties derived from an ensemble of regional climate model simulations, Tellus A, 63, 24-40, 2011.

Krivova, N. A., Balmaceda, L., and Solanki, S. K.: Reconstruction of solar total irradiance since 1700 from the surface magnetic flux, Astron. Astrophys., 467, 335-346, doi:10.1051/0004 6361:20066725, 2007.

Lean, J.: Living with a variable sun, Phys. Today, 58, 32-38, 2005.

Lean, J., Beer, J., and Bradley, R.: Reconstruction of solar irridiance since 1610: implications for climate change, Geophys. Res. Lett., 22, 3195-3198, 1995.

Legutke, S. and Voss, R.: The Hamburg atmosphere-ocean coupled circulation model ECHO-G, DKRZ-Report, German Climate Computer Centre (DKRZ), Hamburg, Germany, 1999.

Lehner, F., Raible, C. C., and Stocker, T. F.: Testing the robustness of a precipitation proxy-based North Atlantic Oscillation reconstruction, Quaternary Sci. Rev., 45, 85-94, doi:10.1016/j.quascirev.2012.04.025, 2012.

Leijonhufvud, L., Wilson, R., Moberg, A., Söderberg, J., Retsö, D., and Söderlind, U.: Five centuries of Stockholm winter/spring temperatures reconstructed from documentary evidence and instrumental observations, Climatic Change, 101, 109-141, doi:10.1007/s10584-009-9650-y, 2010.

Lind, P. and Kjellström, E.: Water budget in the Baltic Sea drainage basin: evaluation of simulated fluxes in a regional climate model, Boreal Environ. Res., 14, 56-67, 2009.

Ljungqvist, F. C., Krusic, P. J., Brattström, G., and Sundqvist, H. S.: Northern Hemisphere temperature patterns in the last 12 centuries, Clim. Past, 8, 227-249, doi:10.5194/cp-8-227-2012, 2012.

Luterbacher, J., Xoplaki, E., Dietrich, D., Rickli, R., Jacobeit, J., Beck, C., Gyalistras, D., Schmutz, C., and Wanner, H.: Reconstruction of sea level pressure fields over the Eastern North Atlantic and Europe back to 1500, Clim. Dynam., 18, 545-561, doi:10.1007/s00382-001-0196-6, 2002.

Mann, M. E., Zhang, Z., Rutherford, S., Bradley, R. S., Hughes, M. K., Shindell, D., Ammann, C., Faluvegi, G., and Ni, F.: Global signatures and dynamical origins of the Little Ice Age and Medieval Climate Anomaly, Science, 326, 1256-1260, doi:10.1126/science.1177303, 2009.

Matthäus, W. and Franck, H.: Characteristics of major Baltic inflows - a statistical analysis, Cont. Shelf Res., 12, 1375-1400, 
doi:10.1016/0278-4343(92)90060-W, 1992.

Meier, H. E. M.: Modeling the age of Baltic Seawater masses: quantification and steady state sensitivity experiments, J. Geophys. Res., 110, C02006, doi:10.1029/2004JC002607, 2005.

Meier, H. E. M.: Modeling the pathways and ages of inflowing saltand freshwater in the Baltic Sea, Estuar. Coast. Shelf S., 74, 717734, 2007.

Meier, H. E. M. and Kauker, F.: Modeling decadal variability of the Baltic Sea: 2. Role of freshwater inflow and large-scale atmospheric circulation for salinity, J. Geophys. Res., 108, 3368, doi:10.1029/2003JC001799, 2003.

Meier, H. E. M., Döscher, R., and Faxen, T.: A multiprocessor coupled ice-ocean model for the Baltic Sea: application to salt inflow, J. Geophys. Res., 108, 3273, doi:10.1029/2000JC000521, 2003.

Meier, H. E. M., Andersson, H. C., Eilola, K., Gustafsson, B. G., Kuznetsov, I., Müller-Karulis, B., Neumann, T., and Savchuk, O. P.: Hypoxia in future climates: a model ensemble study for the Baltic Sea, Geophys. Res. Lett., 38, L24608, doi:10.1029/2011GL049929, 2011a.

Meier, H. E. M., Höglund, A., Döscher, R., Andersson, H., Löptien, U., and Kjellström, E.: Quality assessment of atmospheric surface fields over the Baltic Sea from an ensemble of regional climate model simulations with respect to ocean dynamics, Oceanologia, 53, 193-227, 2011 b.

Meier, H. E. M., Andersson, H., Dieterich, C., Eilola, K., Gustafsson, B., Höglund, A., Hordoir, R., and Schimanke, S.: Modeling the combined impact of changing climate and changing socioeconomic development on the Baltic Sea environment in an ensemble of transient simulations for 1961-2099, Clim. Dynam., online first: doi:10.1007/s00382-012-1339-7, 2012a.

Meier, H. E. M., Andersson, H. C., Arheimer, B., Blenckner, T., Chubarenko, B., Donnelly, C., Eilola, K., Gustafsson, B. G., Hansson, A., Havenhand, J., Höglund, A., Kuznetsov, I., MacKenzie, B. R., Müller-Karulis, B., Neumann, T., Niiranen, S., Piwowarczyk, J., Raudsepp, U., Reckermann, M., RuohoAirola, T., Savchuk, O. P., Schenk, F., Schimanke, S., Väli, G., Weslawski, J.-M., and Zorita, E.: Comparing reconstructed past variations and future projections of the Baltic Sea ecosystem - first results from multi-model ensemble simulations, Environ. Res. Lett., 7, 034005, doi:10.1088/1748-9326/7/3/034005, 2012b.

Min, S.-K., Legutke, S., Hense, A., and Kwon, W.-T.: Internal variability in a 1000-yr control simulation with the coupled climate model ECHO-G - II. El Nino Southern Oscillation and North Atlantic Oscillation, Tellus A, 57, 622-640, 2005.

Nikulin, G., Kjellström, E., Hansson, U., Strandberg, G., and Ullerstig, A.: Evaluation and future projections of temperature, precipitation and wind extremes over Europe in an ensemble of regional climate simulations, Tellus A, 63, 41-55, 2011.

Samuelsson, P., Jones, C. G., Willen, U., Ullerstig, A., Gollvik, S., Hansson, U., Jansson, C., Kjellström, E., Nikulin, G., and Weyser, K.: The Rossby Centre regional climate model RCA3: model description and performance, Tellus A, 63, 4-23, doi:10.1111/j.1600-0870.2010.00478.x, 2011.

Savchuk, O. P., Wulff, F., Hille, S., Humborg, C., and Pollehne, F.: The Baltic Sea a century ago - a reconstruction from model simulations, verified by observations, J. Marine Syst., 74, 485-494, doi:10.1016/j.jmarsys.2008.03.008, 2008.
Seinä, A. and Palosuo, E.: The classification of the maximum annual extent of ice cover in the Baltic Sea 1720-1992, Finn. Inst. of Mar. Res., Helsinki, Meri 20, 1993.

Shapiro, A. I., Schmutz, W., Rozanov, E., Schoell, M., Haberreiter, M., Shapiro, A. V., and Nyeki, S.: A new approach to the long-term reconstruction of the solar irradiance leads to large historical solar forcing, Astron. Astrophys., 529, A67, doi:10.1051/0004-6361/201016173, 2011.

Shindell, D. T., Schmidt, G. A., Mann, M. E., Rind, D., and Waple, A.: Solar Forcing of Regional Climate Change During the Maunder Minimum, Science, 294, 2149-2152, doi:10.1126/science.1064363, 2001.

Spangehl, T., Cubasch, U., Raible, C. C., Schimanke, S., Körper, J., and Hofer, D.: Transient climate simulations from the Maunder Minimum to present day: role of the stratosphere, J. Geophys. Res., 115, D00I10, doi:10.1029/2009JD012358, 2010.

Stevens, D. P.: The open boundary condition in the UK fineresolution antarctic model, J. Phys. Oceanogr., 21, 1494-1499, 1991.

Strandberg, G., Brandefelt, J., Kjellström, E., and Smith, B.: Highresolution regional simulation of the last glacial maximum climate in Europe, Tellus A, 63, 107-125, 2011.

Timmreck, C., Lorenz, S. J., Crowley, T. J., Kinne, S., Raddatz, T. J., Thomas, M. A., and Jungclaus, J. H.: Limited temperature response to the very large AD 1258 volcanic eruption, Geophys. Res. Lett., 36, 5-9, doi:10.1029/2009GL040083, 2009.

Trouet, V., Esper, J., Graham, N. E., Baker, A., Scourse, J. D., and Frank, D. C.: Persistent positive north atlantic oscillation mode dominated the Medieval Climate Anomaly, Science, 324, 78-80, doi:10.1126/science.1166349, 2009.

Unden, P., Rontu, L., Järvinen, H., Lynch, P., Calvo, J., Cats, G., Cuxart, J., Eerola, K., Fortelius, C., Garcia-Moya, J. A., Jones, C., Lenderlink, G., Mcdonald, A., Mcgrath, R., Navascues, B., Nielsen, N. W., Degaard, V., Rodriguez, E., Rummukainen, M., Sattler, K., Sass, B. H., Savijarvi, H., Schreur, B. W., Sigg, R., and The, H.: HIRLAM-5 Scientific Documentation, HIRLAM Report, SMHI, Swedish Meteorological and Hydrological Institute (SMHI), Norrköping, Sweden, 2002.

Uppala, S. M., Kallberg, P. W., Simmons, A. J., Andrae, U., Bechtold, V. D. C., Fiorino, M., Gibson, J. K., Haseler, J., Kelly, A. H. G. A., Li, X., Onogi, K., Saarinen, S., Sokka, N., Allan, R. P., Andersson, E., Arpe, K., Balmaseda, M. A., Beljaars, A. C. M., Berg, L. V. D., Bidlot, J., Bormann, N., Caires, S., Chevallier, F., Dethof, A., Dragosavac, M., Fisher, M., Fuentes, M., Hagemann, S., Holm, E., Hoskins, B. J., Isaksen, L., Janssen, P. A. E. M., Jenne, R., Mcnally, A. P., Mahfouf, J.F., Morcrette, J.-J., Rayner, N. A., Saunders, R. W., Simon, P., Sterl, A., Trenberth, K. E., Untch, A., Vasiljevic, D., Viterbo, P., and Woollen, J.: The ERA-40 re-analysis, Q. J. Roy. Meteorol. Soc., 131, 2961-3012, doi:10.1256/qj.04.176, 2005.

Wagner, S. and Zorita, E.: The influence of vulcanic, solar and $\mathrm{CO}_{2}$ forcing on the temperatures in the Dalton Minimum (1790-1830): a model study, Clim. Dynam., 25, 205-218, doi:10.1007/s00382-005-0029-0, 2005.

Wagner, S., Widmann, M., Jones, J., Haberzettl, T., Lücke, A., Mayr, C., Ohlendorf, C., Schäbitz, F., and Zolitschka, B.: Transient simulations, emperical reconstructions and forcing mechanism for the Mid-holocene hydrological climate in Southern 
Patagonia, Clim. Dynam., 29, 333-355, 2007.

Zillén, L. and Conley, D. J.: Hypoxia and cyanobacteria blooms are they really natural features of the late Holocene history of the Baltic Sea?, Biogeosciences, 7, 2567-2580, doi:10.5194/bg7-2567-2010, 2010.

Zillén, L., Conley, D. J., Andrén, T., Andrén, E., and Björck, S.: Past occurrences of hypoxia in the Baltic Sea and the role of climate variability, environmental change and human impact, Earth-Sci. Rev., 91, 77-92, doi:10.1016/j.earscirev.2008.10.001, 2008.
Zorita, E. and Laine, A.: Dependence of salinity and oxygen concentrations in the Baltic Sea on large-scale atmospheric circulation, Clim. Res., 14, 25-41, 2000.

Zorita, E., Gonzalez-Rouco, J. F., von Storch, H., Montavez, J. P., and Valero, F.: Natural and anthropogenic modes of surface temperature variations in the last thousand years, Geophys. Res. Lett., 32, L08707, doi:10.1029/2004GL021563, 2005. 